\title{
Alcoholization of pyogenichepatic abscess with absolute alcohol in Bama minipigs
}

\author{
RU-GANG ZHANG, XIU-LI ZHANG and YUN-SHENG YANG \\ Institute of Digestive Diseases, Chinese PLA General Hospital, Beijing 100853, P.R. China
}

Received January 16, 2016; Accepted January 26, 2017

DOI: $10.3892 / \mathrm{etm} .2017 .5022$

\begin{abstract}
Pyogenic hepatic abscess (PHA) is a rare, but potentially serious disease. At present, ultrasound-guided or computed tomography-guided percutaneous needle aspiration or catheter drainage is appropriate as a first-line treatment. However, it is difficult to aspirate or drain pus and to select the appropriate antibiotic therapy if the abscess consists of thick pus and polymicrobial confections, or its pathogenic bacterium is multidrug resistant and cryptogenic. Case studies of alcoholization provide a novel method to manage PHA. However, the efficacy and safety of this treatment should be further evaluated. In the present study, the therapeutic efficacy and complications of alcoholization for PHAs in Bama minipigs were investigated. PHAs were prospectively treated by ultrasound-guided percutaneous instillation of absolute alcohol in the abscess cavity. The criteria for considering a successful intervention were met in all minipigs subsequent to alcoholization twice within 14 days. The procedures were well tolerated in all animals, and there were no alcoholic adverse effects or procedure-associated complications. In conclusion, ultrasound-guided percutaneous alcoholization is a safe and effective procedure to manage PHA. The problems of thick pus aspiration and selection of an appropriate antibiotic observed in other treatments were resolved effectively using alcoholization. This technique may reduce the treatment period and possibly become a novel strategy for the management of PHA.
\end{abstract}

\section{Introduction}

Pyogenic hepatic abscess (PHA) is a rare, but potentially life-threatening condition. Population-based studies have reported that the annual average incidence rates of PHA range between 2.3 and 3.6 cases per 100,000 individuals, and the in-hospital case-fatality rates range between 0.0 and $10.0 \%$

Correspondence to: Dr Yun-Sheng Yang, Institute of Digestive Diseases, Chinese PLA General Hospital, 28 Fuxing Road, Beijing 100853, P.R. China

E-mail: yunshengyangdc@163.com

Key words: Bama minipig, absolute alcohol, pyogenic hepatic abscess, ultrasonography in western countries (1-5). In China, the annual average incidence rate is 11.9 per 100,000 individuals and the in-hospital case-fatality rates range between 2.1 and $11.7 \%$ (6-9). At present, ultrasound (US) or computed tomography-guided percutaneous needle aspiration (PNA) or catheter drainage (PCD) is appropriate as a first-line treatment based on systemic antibiotic therapy (5,8,10-15). Although PNA or PCD are equally safe and effective for managing PHA, it remains unclear which procedure should be preferred. However, it is difficult to aspirate or drain pus and to select the appropriate antibiotic treatment in cases where the abscess has thick pus and polymicrobial co-infection, or its pathogenic bacterium is multidrug resistant and cryptogenic in origin $(8,16,17)$.

Absolute alcohol (AA) has the functions of dehydration and fixation. AA has been demonstrated to unselectively cause coagulation necrosis to human and Echinococcus granulosus cells, while it also inactivates the inflammatory mediators and toxins secreted. AA has been demonstrated to unselectively cause coagulation necrosis to human and Echinococcus granulosus cells, while it has also been demonstrated to inactivate the inflammatory mediators and toxins secreted (18-22). Therefore, small hepatocellular carcinoma (18-20), viable hydatid liver cyst $(21)$ and benign hepatic cyst $(16,22)$ can all be safely and effectively managed with alcoholization.

To the best of our knowledge, alcoholization as a possible treatment for PHA has previously been reported in three studies, including two cases with chronic granulomatous disease treated by alcohol instillation $(23,24)$ and a study reporting the treatment in animals by alcohol infusion (25). The alcoholization may result in complete resolution of the abscess, since it resolves the issues of aspiration of thick pus and selection of the appropriate antibiotic treatment (23-28). However, its efficacy and safety should be further evaluated.

The present study established a PHA model in Bama minipigs (29), and the animals were then prospectively treated with the alcoholization. The results demonstrated that the alcoholization is a safe, effective and well-tolerated method to manage PHA.

\section{Materials and methods}

Animals. A total of 6 Chinese clinically healthy Bama minipigs ( 2 females and 4 males; mean body weight, $23.8 \pm 4.1 \mathrm{~kg}$; weight range, $19-29 \mathrm{~kg}$ ) were used in the present study. The minipigs were 9-10 weeks of age and purchased from Animal 
Science and Technology of Guangxi University (Nanning, China). Under specific pathogen-free (SPF) conditions, the animals were kept at $21^{\circ} \mathrm{C}$ in a humidity of $50 \%$, with a $12 \mathrm{~h}$ light/dark cycle from 6:00 to 18:00 and fed with combination diet of $0.36 \mathrm{~kg}$ food $/ \mathrm{kg}$ weight with ad libitum access to water. The study was performed in strict accordance with the recommendations in the Guide for the Care and Use of Laboratory Animals of the National Institutes of Health. The animal use protocol was reviewed and approved by the Institutional Animal Care and Use Committee of the Chinese PLA General Hospital (Beijing, China).

Percutaneous transhepatic alcoholization procedure. Subsequent to exposing the abdominal cavity of the animals, a mixture of methicillin-sensitive S. aureus (ATCC 29213; American Type Culture Collection, Manassas, VA, USA) and autologous venous blood clot was quickly injected into the liver parenchyma. Autologous venous blood was acquired from the splenic vein when the animal abdominal cavity was exposed and autologous venous blood clot was acquired when the blood was automatically coagulated, as previously described (29). After day 21, the animals were diagnosed with PHA and were at abscess-formation stage (29). Next, they were randomly allocated into two groups (15), including the alcoholization treatment and the physiological saline (PS) control groups.

Food was withdrawn $24 \mathrm{~h}$ prior to the intervention with AA. The mini pigs were sedated (29) using intramuscular injection of a solution containing a mixture of $0.83 \mathrm{mg} / \mathrm{kg}$ body weight of zolazepam, tiletamine, xylazine and ketamine and $0.17 \mathrm{mg} / \mathrm{kg}$ body weight butorphanol [all purchased from Department of Pharmacy, Chinese PLA General Hospital (Beijing, China)]. The body weight and rectal temperature were respectively measured with a health meter and mercury thermometer. Venous blood was obtained from the vena cava anterior in order to examine the white blood cell (WBC) count; a catheter $(22 \mathrm{G})$ was inserted into the right ear vein to infuse an anesthetic (29).

All animals were placed in dorsal recumbency, and the abdominal area was clipped and prepared aseptically. Intervention was performed with AA in the alcoholization group. PS was used in the other group, which acted as a negative control. All animals were sacrificed by exsanguination through the femoral artery under full sedation using intramuscular injection of a solution containing a mixture of zolazepam, tiletamine, xylazine and ketamine $(0.83 \mathrm{mg} / \mathrm{kg}$ BW of each drug) and butorphanol (0.17 mg/kg BW) (29). After 21 days of the alcoholization, autopsy was performed for assessing the therapeutic efficacy of the treatment. Samples from the caseous pus of the hepatic abscess were assessed for the bactericidal effect of AA by Gram staining, bacterial cultivation, polymerase chain reaction (PCR) identification and histopathology (29).

Percutaneous transhepatic US-guided interventions. All percutaneous interventions were performed under color Doppler US guidance with an Aloka SSD-650 machine and a $3.5 \mathrm{MHz}$ curvilinear transducer (Hitachi Aloka, Tokyo, Japan). A free-hand technique using an $18 \mathrm{G}$ x $20 \mathrm{~cm}$ disposable PTC needle (Hakko, Nagano-Ken, Japan) was employed for puncturing the abscesses.
The interventions were performed with the PTC needle attached to a $10-\mathrm{ml}$ syringe. The needle was introduced into the abscess cavity through normal hepatic tissue at a depth of at least $1 \mathrm{~cm}$. When the tip of the needle was in the lesion, as much as possible of the purulent material was removed. If the abscess material was not drained at all, then alcoholization was performed by slowly instilling sterile AA ( $\geq 99.7 \%$; $6.17 \pm 0.753 \mathrm{ml}$ ) until the lesion progressively became diffuse hyperechogenic $(23,24)$. The procedure was repeated 7 days later when required.

Bactericidal effect of AA. Samples from the caseous pus of the hepatic abscess were assessed for the bactericidal effect of AA by Gram staining, bacterial cultivation, PCR identification and histopathology (29). The bactericidal effect of AA was also assessed by cultural method in AA or penicillin solution.

First caseous pus of mung bean from a PHA was spread on glass slides and subjected to Gram staining following air-drying. Caseous pus was inoculated into LB broth and incubated overnight at $37^{\circ} \mathrm{C}$ with agitation (200 rpm). The bacterial suspension of $0.1 \mathrm{ml}$ was inoculated on an LB agar plate and immovably incubated overnight at $37^{\circ} \mathrm{C}$. The bacterial precipitate was generated by the centrifugation of $3 \mathrm{ml}$ bacterial suspension for $10 \mathrm{~min}$ at $4^{\circ} \mathrm{C}$ and $4,000 \mathrm{x}$ g then the chromatin DNA was extracted using the E.Z.N.A. ${ }^{\circledR}$ Bacterial DNA kit (Omega Bio-Tek, Inc., Norcross, GA, USA) and lysostaphin (Sangon Biotech, Co., Ltd., Shanghai, China) following the manufacturers protocol, as previously described (29). The primer pairs of the thermostable nuclease A gene (nисA) were, 5'-GCGATTGATGGTGATACGGTT-3' and 5'-AGC CAAGCCTTGACGAACTAAAGC-3'. The cycling conditions were as follows: $94^{\circ} \mathrm{C}$ for $45 \mathrm{sec}$ followed by 30 cycles at $94^{\circ} \mathrm{C}$ for $30 \mathrm{sec}, 55^{\circ} \mathrm{C}$ for $30 \mathrm{sec}$ and $72^{\circ} \mathrm{C}$ for $60 \mathrm{sec} ; 72^{\circ} \mathrm{C}$ for $120 \mathrm{sec}$ and held at $4^{\circ} \mathrm{C}$. The desired fragment length was 279 bp following PCR. S. aureus strains ATCC 29213 served as positive controls, and deionized water served as the negative control. All samples were analyzed in triplicate.

The samples of PHA were fixed for $24 \mathrm{~h}$ with $4 \%$ formaldehyde in phosphate-buffered saline, and then processed through graded concentrations of ethanol $(75,85,95$ and $100 \%$ ) and xylene, embedded in paraffin wax, cut into 3-5 $\mu \mathrm{m}$ sections, rehydrated and finally stained with hematoxylin and eosin (H\&E).

Caseous pus was then respectively cultured in AA and penicillin solutions (diluted with LB broth) overnight at $37^{\circ} \mathrm{C}$ with agitation (200 rpm) and observed. A bacterial suspension of $0.1 \mathrm{ml}$ was inoculated into the LB agar plate and incubated overnight at $37^{\circ} \mathrm{C}$ and observed.

Outcome measurement. A successful percutaneous intervention was defined as improvement with decreased temperature if the animals initially had fever, decreased WBC if they presented leukocytosis (30), and total or partial organization of purulent material as observed by pathology.

Statistical analysis. Statistical analysis was performed with SPSS statistical software (version 16.0; SPSS, Inc., Chicago, IL, USA). All continuous variables are expressed as the mean \pm standard deviation. Categorical variables are reported as percentages. Quantitative variables were compared by 

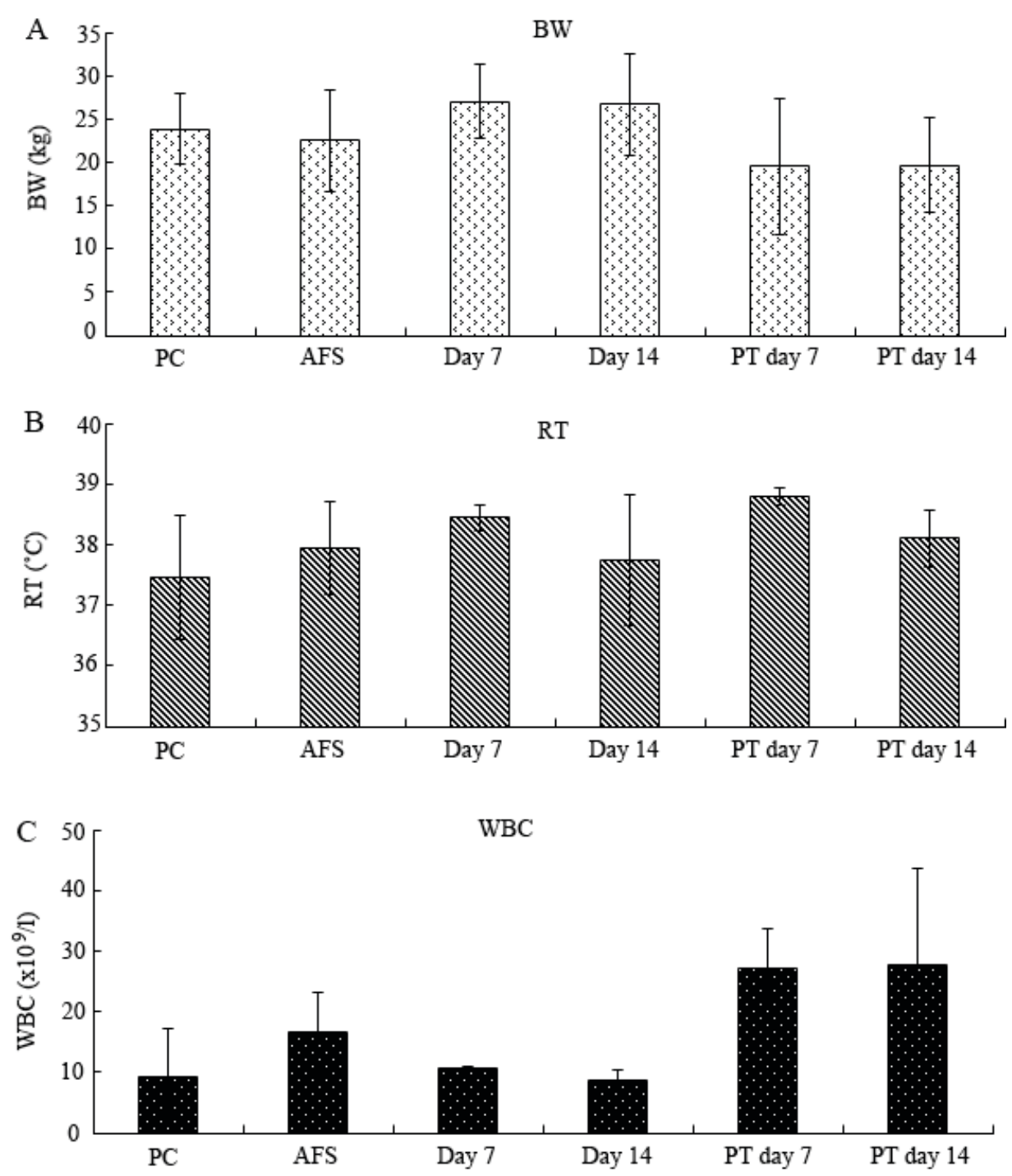

Figure 1. Changes in (A) BW, (B) RT and (C) WBC in Bama minipig with PHA subsequent to management by ultrasound-guided instillation with PS or AA. The WBC in PS-treated minipigs was significantly increased compared with the normal physiological condition and AA-treated minipigs $(\mathrm{P}<0.05)$. However the difference between PS and AA on day 7 of treatment was not significant $(\mathrm{P}>0.05)$. However, BW and RT were not significantly different between the two groups ( $\mathrm{P}=0.484$ and $\mathrm{P}=0.434$, respectively). WBC counts of day 7 of PS treatment vs. PC and day 14 of AT. WBC counts of day 14 of PS treatment vs. PC, day 7 and 14 of AT. BW, body weight; RT, rectal temperature; WBC, white blood cell count; PS, physiological saline; AA, absolute alcohol; PT, PS-treated minipigs; PC, normal physiological condition; AT, AA-treated minipigs.

one-way analysis of variance (ANOVA) and the F-test, while multiple comparisons were executed by one-way ANOVA and the least significant difference method. All significance tests were two-tailed, and differences with $\mathrm{P}<0.05$ were considered to be statistically significant.

\section{Results}

Percutaneous transhepatic alcoholization in Bama minipig with PHA. During PHA treatment with AA or PS all animals presented anorexia, however none had pyrexia. Leukocytosis was identified in all animals treated with PS (control group). Normal reference values of rectal temperature (RT) and WBC count in minipigs are $38.0-39.5^{\circ} \mathrm{C}$ and $7.53-16.82 \times 10^{9} / 1$ respectively (31).

The average mean WBC count when the animals were treated for 7 days with PS was significantly higher compared with the healthy state, being the WBC counts prior to the experiment $[\mathrm{P}=0.015 ; 95 \%$ confidence interval $(\mathrm{CI})$ of 4.05-31.35] and that of animals treated for 14 days with AA $(\mathrm{P}=0.034$; $\mathrm{CI}, 1.64-35.06)$. The WBC count of the six minipigs under the healthy state was respectively $12.7,7.3,7.9,7.0,8.3$ and $13.6 \times 10^{9} / 1$. The mean was $9.467 \times 10^{9} / 1$ and standard deviation was 2.903. No significant difference was observed between PS and AA on day 7 of treatment $(\mathrm{P}=0.055)$. In addition, the average WBC count in animals treated for 14 days with PS was significantly higher compared with the healthy state value $(\mathrm{P}=0.012$; CI, 4.80-32.10) and that of animals treated for 7 and 14 days with $\mathrm{AA}[\mathrm{P}=0.046(\mathrm{CI}, 0.39-33.81)$ and $\mathrm{P}=0.028(\mathrm{CI}$, 2.39-35.81), respectively]. However, the average body weight $(\mathrm{F}=1.028, \mathrm{P}=0.434)$ and the abscess size $(\mathrm{F}=1.116, \mathrm{P}=0.411)$ were not significantly different between the two groups (Fig. 1).

As observed, all 6 animals had a single lesion (cross section, $4.86 \pm 2.47 \mathrm{~cm}^{2}$ ) at the left hepatic lobe, which 

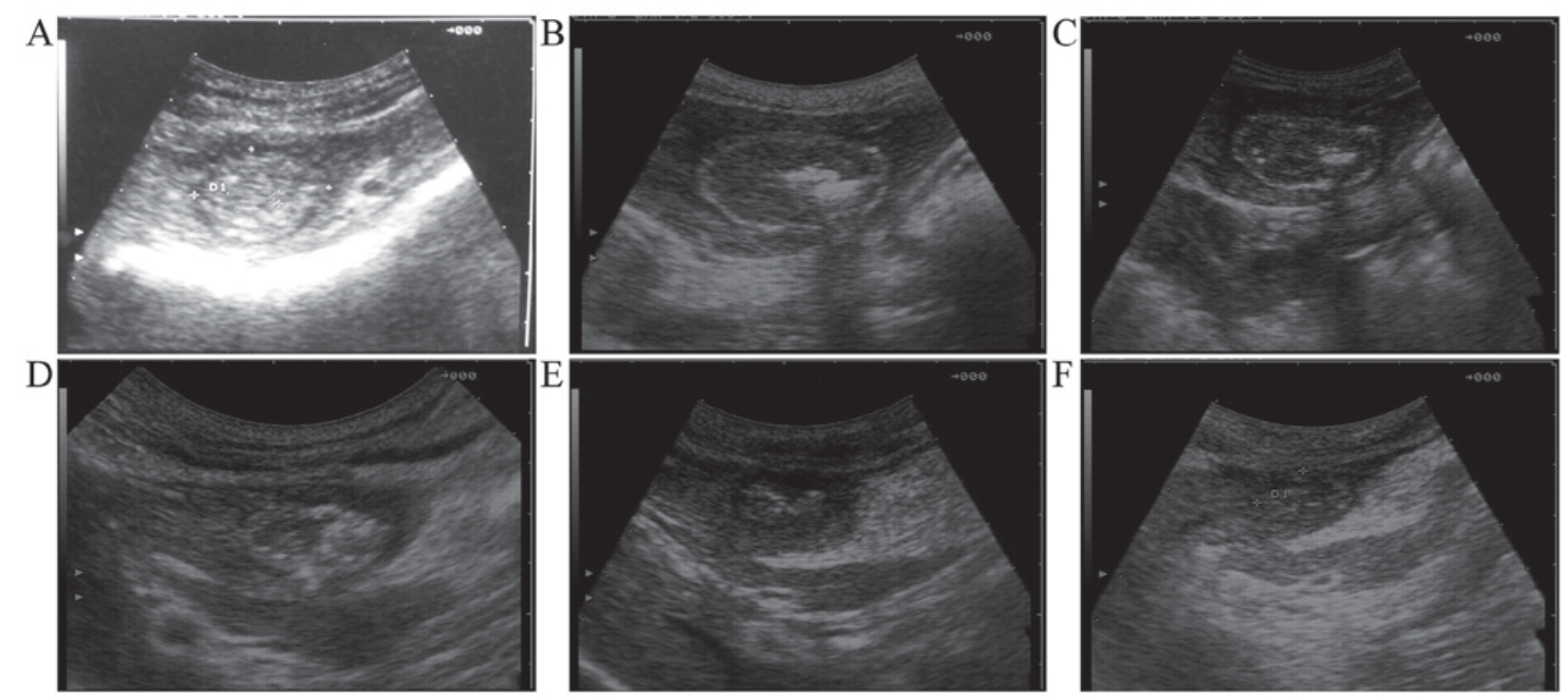

Figure 2. Ultrasound-guided percutaneous intervention (cross section) for the management of pyogenic hepatic abscess in Bama minipigs. (A) Prior to intervention, mixed echogenicity $(3.6 \times 1.7 \mathrm{~cm})$ with an evident ring of hypoechogenic liver edema surrounding the lesion was observed. Alcoholization treatment with absolute alcohol after (B) 7 days and (C) 14 days, showing mixed echogenicity without a ring of hypoechogenic liver edema $(3.2 \times 2.2 \mathrm{and} 3.0 \times 1.9 \mathrm{~cm}$, respectively). (D) Mixed echogenicity $(3.1 \times 1.4 \mathrm{~cm})$ with an evident ring of hypoechogenic liver edema from a control group minipig, prior to PHA treatment. (E) Mixed anechogenic lesion $(2.4 \times 1.5 \mathrm{~cm})$ with a clear ring of hypoechogenic liver edema at 7 days after PS treatment. (F) Mixed echogenicity (1.9x1.2 cm) without a ring of hypoechogenic liver edema at 14 days after PS treatment. PHA, pyogenic hepatic abscess; PS, physiological saline.

included round to oval mixed echogenicity with a ring of hypoechogenic liver edema surrounding the lesion. On day 7 following the therapeutic procedure, the ring of hypoechogenic liver edema disappeared in the AA group not in the PS group (Fig. 2). On day 14 following the therapeutic procedure, the mixed echogenicity remained apparent, but the ring of hypoechogenic liver edema had disappeared in the two groups. The autopsy results subsequent to sacrifice on day 21 revealed that the abscess wall attached to thick gray-yellow pus was thin, pale and tenacious (Fig. 3A). Histopathology indicated that the abscess wall was compact, thick and even, and its WBC count was lower in the AA group. The abscess wall was all lax, thin and uneven, and its WBC count was more in the PS group.

Bactericidal effects of AA. S. aureus bacteria from the caseous pus of the hepatic abscess were killed following incubation in $\mathrm{AA}$ for 20 and $30 \mathrm{~min}$ in $\mathrm{AA}$; however, the bacteria were still alive when incubated for $10 \mathrm{~min}$ in AA or in penicillin $\mathrm{G}$ sodium $(9.6 \mathrm{mg} / \mathrm{ml}$ in PS). The color of the suspension was evenly yellowish after the caseous pus was inoculated into the Luria-Bertani (LB) broth and incubated at $37^{\circ} \mathrm{C}$ overnight with agitation. Typical colonies of $S$. aureus were identified after the bacterial suspension was inoculated into the LB agar plate and incubated overnight.

Typical colonies of $S$. aureus were observed following the caseous pus of the hepatic abscess, on day 14 of alcoholization or PS treatment cultured in LB broth then on an LB agar plate (Fig. 3B). Numerous Gram-positive thyrsiform cocci were detected after the caseous pus of the liver abscess was smeared on glass slides and Gram staining was performed (Fig. 3C). In addition, the desired fragment was identified following PCR amplification (Fig. 3D). According to histopathological analysis results, the abscess contents were organized fully in 2 minipigs and partially in 1 minipig in the AA group, and fully in 1 minipig and partially in 2 minipigs in the PS group.

The success rate of PHA treatment was $100 \%$ in the AA group subsequent to alcoholization twice, with full or partial organization of the abscess materials and normal WBC count. However, none of the animals was consistent with the criteria of successful percutaneous intervention in the PS group. No complications, such as hepatic hemorrhage, hepatonecrosis and mortality, were detected in any of the animals during AA or PS treatment.

\section{Discussion}

Image-guided PNA or PCD based on systemic antibiotic therapy is currently the preferred first-line management over surgical drainage, as in open or laparoscopic drainage, treating liver abscesses in the majority cases. However, it is difficult to aspirate or drain pus, and to select the appropriate antibiotic treatment when the abscess has thick pus and polymicrobial co-infection, or its pathogenic bacteria are multidrug resistant and cryptogenic in origin $(8,16,17)$.

Thick pus is a known characteristic in the Bama minipig PHA model and cannot be directly aspirated (29). Therefore, AA instillation was selected in the present study for treating PHA. Subsequent to instillation of AA twice, the abscess contents were fully or partially organized, and the WBC content was restored to the normal values. These results suggested that AA may not only kill the super and inner bacteria in the caseous pus, but also inactivate their toxins and inflammatory mediators secreted. Although the achievement ratio of treatment was $100 \%$, S. aureus bacteria were identified in the caseous pus of all minipigs, along with a number of Gram-positive thyrsiform cocci, when cultured microbiologically. Furthermore, S. aureus bacteria in the caseous pus were 
A
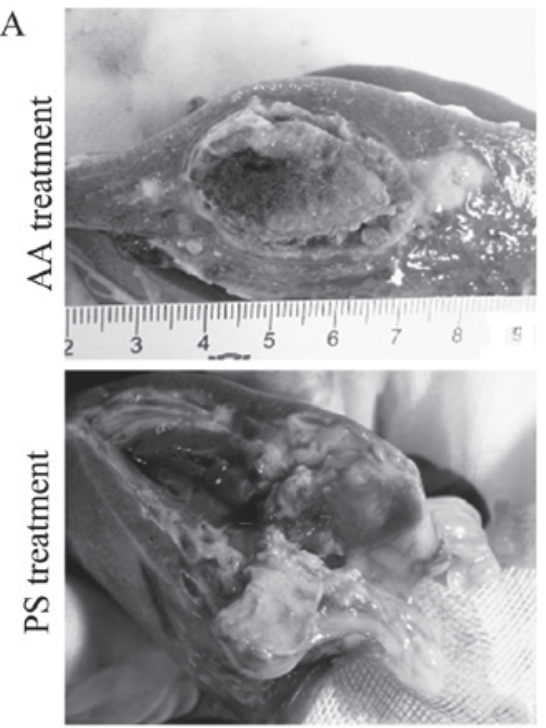

D
B
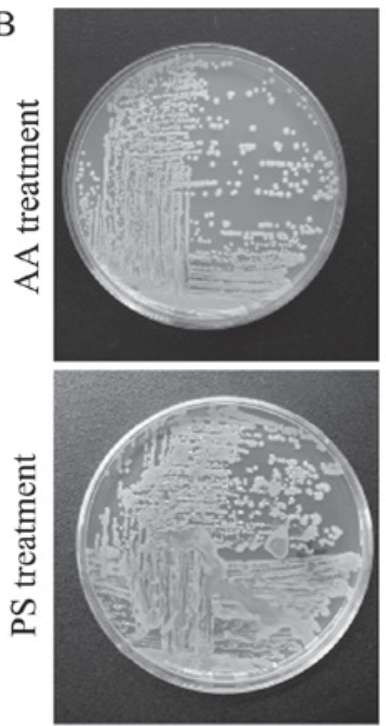
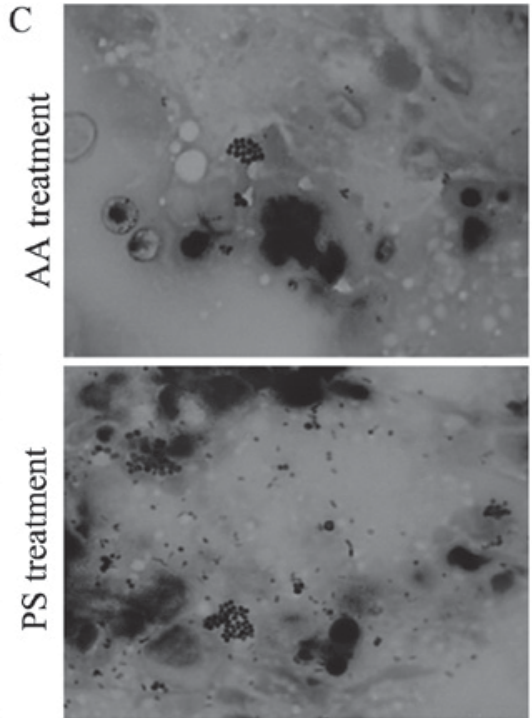

5

6

water

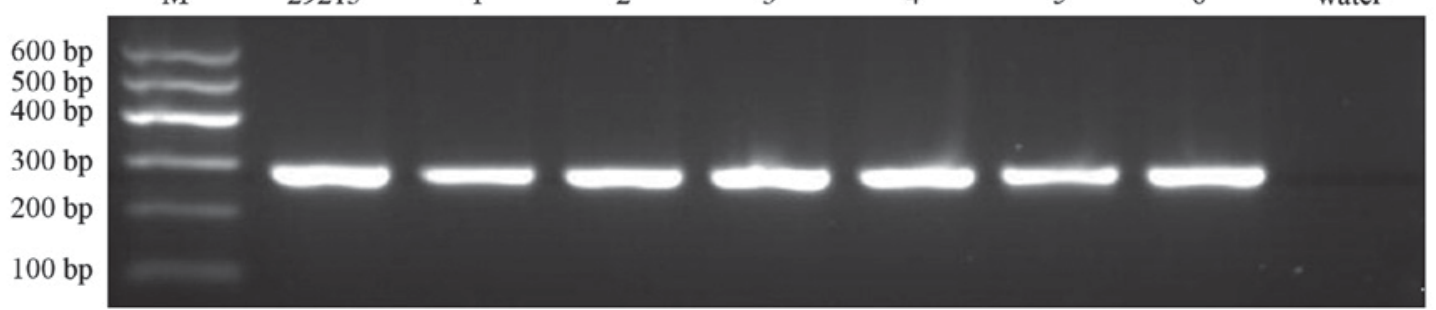

Figure 3. Results obtained from autopsy, pus culture, Gram staining and PCR identification in Bama minipig with PHA. (A) Thick gray-yellow pus attached to thin and pale abscess wall, with fully organized abscess content at 14 days after alcoholization (cross section, $2.5 \times 2.0 \mathrm{~cm}$ ) and partly organized abscess content at 14 days after treatment with PS (cross section, $2.1 \times 1.6 \mathrm{~cm}$ ). (B) Typical colonies of $S$. aureus identified following culture of caseous pus on LB agar plate at 14 days after alcoholization or PS treatment. (C) Gram-positive thyrsiform cocci identified in caseous pus by Gram staining at 14 days after alcoholization or PS treatment, with a higher number of cocci observed in the PS treatment group (magnification, $x 1,000$ ). (D) Pathogenic bacteria of PHA identified by PCR with nucA oligonucleotide primers. From left to right, the gel shows the results for standard molecular marker (M), S. aureus ATCC 29213, minipigs 1-6 and deionized water. PHA, pyogenic hepatic abscess; PS, physiological saline; AA, absolute alcohol; PCR, polymerase chain reaction.

not completely killed after incubation in AA for 10 min. Thus, the experimental results of the present study suggested that AA can only perform limited osmosis and bactericidal effect in the caseous pus (17).

The body weight and the size of the abscess cavity were not significantly different between the AA and PS groups subsequent to the alcoholization, which may be associated with no systemic antibiotic therapy $(23-25,30)$. The rectal temperature was not significantly different between the two treatment groups, which was possibly associated with the cold and dry ambient air $\left(26^{\circ} \mathrm{C}\right)$ in the operating room and the applied general anesthesia, since the anesthesia and surgical procedure can synergistically interfere with normal thermoregulation (32).

During the alcoholization, the procedure was well tolerated in the minipigs. Following the alcoholization, there were no alcoholic adverse effects, procedure-associated complications or mortality observed in the minipigs. Therefore, the present study suggests that the US-guided percutaneous alcoholization is a safe and effective procedure for PHA treatment, as also stated in previous reports (23-25).

In the present study, the criteria for determining a successful intervention were met following alcoholization with AA rather than with $95 \%$ alcohol, as used previously (23-25). AA was used in the current experiments since the thick pus from PHA was not drained at all. In order to avoid the attenuation of alcohol density injected and obtain the maximal function of dehydration and fixation (22), PHA was managed with AA rather than $95 \%$ alcohol.

The present study has three limitations. Firstly, measuring the temperature of minipigs was difficult since they were easily agitated. Thus, a more simple and accurate method to record the temperature, such as biochips, should be used in future studies. Furthermore, the present results should be confirmed in study including a larger number of Bama minipigs. Finally, significantly different results could be obtained between the AA and PS groups if the observable period was longer and systemic antibiotic therapy was added. These shortcomings may be addressed in upcoming studies.

In conclusion, US-guided percutaneous alcoholization is a safe and effective procedure to manage PHA. The alcoholization may shorten the treatment period and become a new method to manage PHA.

\section{Acknowledgements}

The current research was supported by the China Postdoctoral Science Foundation (grant no. 20100471817) and Army 11th Five Important Special Financial Assistance (grant no. 08Z037). 


\section{References}

1. Kaplan GG, Gregson DB and Laupland KB: Population-based study of the epidemiology of and the risk factors for pyogenic liver abscess. Clin Gastroenterol Hepatol 2: 1032-1038, 2004

2. Meddings L, Myers RP, Hubbard J, Shaheen AA, Laupland KB, Dixon E, Coffin C and Kaplan GG: A population-based study of pyogenic liver abscesses in the United States: Incidence, mortality, and temporal trends. Am J Gastroenterol 105: 117-124, 2010.

3. O'Farrell N, Collins CG and McEntee GP: Pyogenic liver abscesses: Diminished role for operative treatment. Surgeon 8: 192-196, 2010.

4. Alkofer B, Dufay C, Parienti JJ, Lepennec V, Dargere S and Chiche L: Are pyogenic liver abscesses still a surgical concern? A Western experience. HPB Surg 2012: 316013, 2012.

5. Heneghan HM, Healy NA, Martin ST, Ryan RS, Nolan N, Traynor $\mathrm{O}$ and Waldron R: Modern management of pyogenic hepatic abscess: A case series and review of the literature. BMC Res Notes 4: 80, 2011

6. Zhu X, Wang S, Jacob R, Fan Z, Zhang F and Ji G: A 10-year retrospective analysis of clinical profiles, laboratory characteristics and management of pyogenic liver abscesses in a chinese hospital. Gut Liver 5: 221-227, 2011.

7. Lok KH, Li KF, Li KK and Szeto ML: Pyogenic liver abscess: Clinical profile, microbiological characteristics, and management in a Hong Kong hospital. J Microbiol Immunol Infect 41: 483-490, 2008.

8. Chen SC, Tsai SJ, Chen CH, Huang CC, Lin DB, Wang PH, Chen CC and Lee MC: Predictors of mortality in patients with pyogenic liver abscess. Neth J Med 66: 196-203, 2008.

9. Tsai FC, Huang YT, Chang LY and Wang JT: Pyogenic liver abscess as endemic disease, Taiwan. Emerg Infect Dis 14: 1592-1600, 2008.

10. Mezhir JJ, Fong Y, Jacks LM, Getrajdman GI, Brody LA, Covey AM, Thornton RH, Jarnagin WR, Solomon SB and Brown KT: Current management of pyogenic liver abscess: Surgery is now second-line treatment. J Am CollSurg 210: 975-983, 2010

11. Balint TD, Bailey BM, Mendelson KG and Pofahl W: Hepatic abscess: Current concepts in diagnosis and treatment. Curr Surg 58: 381-384, 2001

12. Ferraioli G, Garlaschelli A, Zanaboni D, Gulizia R, Brunetti E, Tinozzi FP, Cammà $\mathrm{C}$ and Filice $\mathrm{C}$ : Percutaneous and surgical treatment of pyogenic liver abscesses: Observation over a 21-year period in 148 patients. Dig Liver Dis 40: 690-696, 2008.

13. Chung YF: Pyogenic liver abscess-predicting failure to improve outcome. Neth J Med 66: 183-184, 2008.

14. Yu SC, Ho SS, Lau WY, Yeung DT, Yuen EH, Lee PS and Metreweli C: Treatment of pyogenic liver abscess: Prospective randomized comparison of catheter drainage and needle aspiration. Hepatology 39: 932-938, 2004.

15. Onder A, Kapan M, Böyük A, Gümüș M, Tekbaș G, Girgin S and Tacyildiz IH: Surgical management of pyogenic liver abscess. Eur Rev Med Pharmacol Sci 15: 1182-1186, 2011.

16. Lohela P: Ultrasound-guided drainages and sclerotherapy. Eur Radiol 12: 288-295, 2002.

17. Laborda A, De Gregorio MA, Miguelena JM, Medrano J, Gómez-Arrue J, Serrano C, de Blas I, Gimenez M and D'Agostino H: Percutaneous treatment of intrabdominal abscess: Urokinase versus saline serum in 100 cases using two surgical scoring systems in a randomized trial. Eur Radiol 19: 1772-1779, 2009.
18. Shiina S, Tateishi R, Imamura M, Teratani T, Koike Y, Sato S, Obi S, Kanai F, Kato N, Yoshida H, et al: Percutaneous ethanol injection for hepatocellular carcinoma: 20-year outcome and prognostic factors. Liver Int 32: 1434-1442, 2012.

19. Mahnken AH, Bruners P and Günther RW: Local ablative therapies in HCC: Percutaneous ethanol injection and radiofrequency ablation. Dig Dis 27: 148-156, 2009.

20. Kim SR, Imoto S, Nakajima T, Ando K, Mita K, Taniguchi M, Sasase N, Matsuoka T,Kudo M and Hayashi Y: Well-differentiated hepatocellular carcinoma smaller than $15 \mathrm{~mm}$ in diameter totally eradicated with percutaneous ethanol injection instead of radiofrequency ablation. Hepatol Int 3: 411-415, 2009.

21. Giorgio A, Tarantino L, de Stefano G, Francica G, Esposito F, Perrotta A, Aloisio V, Farella N, Mariniello N, Coppola C and Caturelli E: Complications after interventional sonography of focal liver lesions: A 22-year single-center experience. J Ultrasound Med 22: 193-205, 2003.

22. Yan-Hong F, Lin-Xue Q, Hai-Ma G, Qing Z, Yu G and Xiangdong H: Sclerotherapy of simple hepatic cysts by repeated aspiration and alcohol instillation. Turk J Gastroenterol 23: 359-365, 2012.

23. Alberti D, Borsellino A, Locatelli C, Nani R, Cheli M, Torre G, Notarangelo L and Locatelli G: Percutaneous transhepatic alcoholization: A new therapeutic strategy in children with chronic granulomatous disease and liver abscess. Pediatr Infect Dis J 21: 1081-1083, 2002.

24. Angelino G, Natali GL, Falappa P, Folgori L, Moretti R, Cantarutti N, Di Matteo G, Chiriaco M, Rossi P, Roos D, Aiuti A and Finocchi A: Successful treatment with percutaneous transhepatic alcoholization of a liver abscess in a child with chronic granulomatous disease. Pediatr Infect Dis J 30: 819-820, 2011.

25. Zatelli A, Bonfanti U, Zini E, D'Ippolito P and Bussadori C: Percutaneous drainage and alcoholization of hepatic abscesses in five dogs and a cat. J Am Anim Hosp Assoc 41: 34-38, 2005.

26. Lublin M, Bartlett DL, Danforth DN, Kauffman H, Gallin JI, Malech HL, Shawker T, Choyke P, Kleiner DE, Schwartzentruber DJ, et al: Hepatic abscess in patients with chronic granulomatous disease. Ann Surg 235: 383-391, 2002.

27. Hussain N, Feld JJ, Kleiner DE, Hoofnagle JH, Garcia-Eulate R, Ahlawat S, Koziel DE, Anderson V, Hilligoss D, Choyke P, et al: Hepatic abnormalities in patients with chronic granulomatous disease. Hepatology 45: 675-683, 2007.

28. Chen LE, Minkes RK, Shackelford PG, Strasberg SM, Kuo EY and Langer JC: Cut it out: Managing hepatic abscesses in patients with chronic granulomatous disease. J Pediatr Surg 38: 709-713, 2003.

29. Zhang RG, Wang XD, Zhang XL and Yang YS: An experimental model for Staphylococcus aureus hepatic abscess in Bama minipig. Genet Mol Res 13: 7113-7122, 2014.

30. Liu CH, Gervais DA, Hahn PF, Arellano RS, Uppot RN and Mueller PR: Percutaneous hepatic abscess drainage: Do multiple abscesses or multiloculated abscesses preclude drainage or affect outcome? J Vasc Interv Radiol 20: 1059-1065, 2009.

31. $\mathrm{Hu} \mathrm{JH}$, Yao M and Cui SF: Laboratory animal science course [M]. Shanghai, Shanghai Scientific \& Technical Publishers, pp107-113,2009.

32. Carpenter L and Baysinger CL: Maintaining perioperative normothermia in the patient undergoing cesarean delivery. Obstet Gynecol Surv 67: 436-446, 2012. 